\title{
Educational religious corresponding plurality
}

\author{
Babak Shamshiri ${ }^{1}$, Beheshteh Safarpoor ${ }^{2 *}$ \\ ${ }^{I}$ Faculty member of Shiraz university \\ ${ }^{2} P h D$ student in philosophy of education at shiraz university, farhangian university \\ *Corresponding author E-mail: safarpour1391@yahoo.com
}

\begin{abstract}
The aim of this paper is to study the relationship between pluralism and religious education in Education. On the whole, the main aim of this writing is to recite the possibility and assumptions of a religious model corresponding plurality with the present developments and to discuss and study the features of an efficient and responsive religious education against the changes in the world without borders. The main questions in this research are: 1. is it possible to design a religious approach that can be associated with pluralism? 2. What consequences can this view have for education? Methods to answer the above questions using the documentary method and referring to the studies including scholarly books and articles have been scientific-Research and analysis-inference i.e. the method based on rational reasoning and inference. In order to answer the first and the second questions analytical and inferential methods were used, respectively. In other words, According to the clarification of the concept and meaning of pluralism, the possibility of its aggregation with religious is deductible and the consequences of the sum of the two can be studied. In conclusion, findings showed that it was possible to sum between pluralism and Islamic education.
\end{abstract}

Keywords: Religious Education, Pluralism, Islamic Education.

\section{Introduction}

Tendency to religion is one of the most original and most ancient human tendencies that history has remembered and remembers it, and in any era and society at least some evidence of religious tendency had been present. So its history is as old as the universe and human life. In this case, if the purpose of religious education in the general sense of the phrase, is to train religion-oriented and pious human beings, then the purpose of Islamic religious education is to educate human beings who rationally and wholeheartedly believe in the principles of Islam, and also act in accordance with its rules and orders both in the individual and social context. Of course, as studying Islamic history shows, different Islamic movements and dispositions were grown. Following the development of each of these movements, different approaches to religious education such as rational, traditional and mystical approaches were created [1]. In this paper by religious education we mean Islamic religious education. Religious education should adopt an inclusive and universal approach for itself to be able to both, to act beyond the space and beyond the time, and include in itself the whole range of human existence and scope of various areas of knowledge. In addition, taking the time into account, recognizing the problem and having knowledge about the audience are also among the requirements for religious education because the educational processes are always done by human being with human being and for human being and he/she cannot ignore these features and needs, the time and areas of human life. Also in this regard, cognitive, monopolistic, inclusive and pluralistic approached are raised in a religious attitude. From an exclusive point of view, salvation and absolute truth exists only for a particular religion and it is not a fragmented issue. In an inclusive view a particular tradition is indicative of the ultimate truth. Despite the acceptance of the claim that religious belongs only to the absolute right, an inclusive person accepts that followers of other religions while strictly adhering to the realities and maintaining their own historical identity to be more broad-minded and generous towards each other. Also in view of pluralism belief in truth is the same in all of the religious traditions though it may be given different interpretations. [2]. It seems that pluralism approach may also be able to be the basis of religious education orientation in the era of today's extensive cultural interactions. From this point o view we can consider the followers of divine and Ibrahimic religions subject to switching towards the right truth of religion, that is, true faith in God and the principles of faith and enjoying spirituality based on religious morality under the pluralist perspective." In this discussion emphasis will be placed firstly on religious education and then religious education will be studied as an important issue and category in achieving the reality from the view point of pluralism. 


\section{Statement of the problem}

If educational systems are to maintain their efficiency, they should remove the static and recession mode of their objectives, principles and practices and make themselves consistent with changes in circumstances so that they can prepare themselves to rationally confront and deal with the changes unless they will be doomed to failure and incompetence. Unlike the past times, in modern era people are widely exposed to other cultures and religious and social values. This access has been expanded so that even from the view point of some scholars a change in religious Attitudes with transnational and global look and approach has been emerged that may lead to the formation of a kind of religion. Fokow (1983) believes that the contemporary era is the age of being close together, the age of far and close affinity, and at the same time the age of scattering and separation. For this reason, today's world is a multi-cultural environment and people live in an open, flexible and even complex space. This means that culture in today's world, has been abandoned from the context and territory of national lands and what makes up people's meaning system, is sometimes a mix of multiple cultures and subcultures with different origins. [8]. although it seems that in the contemporary era, cultural spaces have begun to collapse, a fertile field for reconstruction and rehabilitation of particular cultures has also been created. In the issue of religious education if we accept that sooner or later we must welcome a unified and integrated world, like it or not we will face the following questions:- 1 . Is it possible to design a religious education approach that can correspond with pluralism? - 2. What consequences may this type of training have for Islamic education?

\section{The importance and the necessity the issue}

Education has many dimensions and aspects that should be considered in studying the category of religious education and designing a comprehensive and overall educational theory and approach because training happens in its multilateral and complete sense when all of its dimensions and aspects to be considered. One of the important dimensions of education is religious and spiritual training in education through which every effort is made for people's attitudes and behaviors to follow their beliefs and religious convictions system. Religious education dimension should ultimately lead to infiltration and penetration of spirituality within the human being. In this regard training the nature of searching for the God, sense of worship and prayer, strengthening the relationship of man with God, consolidating and developing the scholarly, passionately, and falling in love relationship with Lord of lords and the only beloved, and nurturing the religion oriented mood and behavior in instructors are among the objectives of this dimension of education. In addition, paying special attention to spiritual and religious divine education, especially in our Islamic society is of great importance and necessity. If education is to be based on religious approach, all dimensions of education should be studied from the view point of this approach. In this meaning and interpretation, all aspects of the training (social training, emotional, intellectual and rational and ... training) get religious sense and concept. Religious plurality is an inevitable reality; however, the important thing is how to encounter this reality and even more important than that one is the fact that being engaged in these challenges is an essential part of our intellectual, social, and educational needs of our society and any indifference about it is not favored.

It seems that one of the most important and challenging concept of changes in contemporary era especially with the rapid and wonderful development in information and communication technology for religious training is the changes in approaches and previous structures is knowledge and method that has been reintegrating. For this reason it is necessary that religious education approaches, by passing the traditional approaches such as privacy barring approach or restrictive approach insist on modern educational approaches such as privacy expansion or expansion approach. In other words, religious education in the present era should have genuine, rational and grower of the ability feature to interact with and neglect the different cultures because complete and thorough acceptance or negation of other people will not be a wise and effective logic [8].

\section{Objectives}

Being specific and monopoly structure is among the structures that religious education in the past took place relying on it within the context and the light of a cult and mainly in the realm of a religion's values so that the possibility of presence of other religious settings was very poor. Therefore, religious education was exclusively directed to a particular religion while the religious education of today is more indeterminate and uncontrollable. Thus, this type of training can no longer be based solely on exclusive and one-ritual attitudes. For this reason, it is necessary some kind of approach, bearing the concept of acceptance of other religions and cultures logical and right positions to be considered in a more broad way. According to Robertson (1992) the process of globalization highlights the differences and in addition to demonstrating the differences, makes religions to meet the claims of other religions as well. Moreover, 
because of dependence of education on the era and generation requirements, efficiency of religious education also requires wise and insightful adaptation of existing conditions and current developments. For this reason, religious education always bears heavy responsibility and whenever some problems appear proportional to the time and encounter religious education to the difficulties, religious education should deal with them in a prudent and efficient manner. On the other hand, exposure of educational systems with religious category can be studied in the continuum that there are highly religious systems and on one side of it and on its other side there are secular or non-religious educational systems [8]. Moreover, religious education should adopt for itself a comprehensive and universal approach to be able to both, to act beyond the space and beyond the time, and include in itself the whole range of human existence and scope of various areas of knowledge. In addition, taking the time into account, recognizing the problem and having knowledge about the audience are also among the requirements for religious education because the educational processes are always done by human being with human being and for human being and he/she cannot ignore these features and needs, the time and areas of human life. A pluralistic approach to religious education can be associated with adopting flexible, open and more balanced positions and also can make the ground ready for interaction and inevitable coexistence in the world today.

\section{Religious education}

As mentioned before education ha different dimensions and aspects. One of its important dimensions is religious and spiritual one through which it is attempted to develop awareness, knowledge, attitudes and religious behaviors internally and sustainably in trainees so that their thoughts, attitudes and behaviors follow the system of their religious beliefs [6]. In this section it is appropriate to make philosophical views, assumptions and thoughts that are common in religious education clear.

\section{Fundamental assumptions of religious education}

Discussion in the realm of religious education should take place from two perspectives. Firstly, concerning the aspect of the impact of religion and its teachings on the relationship between human being and himself and between him and the world around him, this includes: 1. Human being's relationship with himself 2 . Human being's relationship with others 3. Human being's relationship with material world (concrete world). 4. Human being's relationship with kingdom of heaven (the spiritual world) [6]. Secondly, concerning the human being's relation with religion; unlike the previous section in which subject of religious education was related to human being and in general to the universe, in this section religion itself is raised a subject that should be identified and consequently, its relationship with education. In other words, this category deals with the way of recognition, understanding and finally human being's relations with religion. From this perspective, religious training will be the process of training the trainee in order to encounter the religion. The main elements of religious education generally involve two assumptions as follows.

\section{Properties of religious education}

After explaining the underlying assumptions of religious education, it was the turn of logical inferences from these assumptions. The most important characteristics of religious education according to Shamshiri [6] are as follows: Emphasis on the religious motivations as a first step in religious education; the second feature is the emphasis on the ethical dimensions of religious education and emphasis on the aesthetic dimensions of religious education also The role of love in religious education, relying on personal experiences in the field of religious education, cognitive role of the worship and finally the most important discussion here is the feature of tolerance and negligence in religious education. Ibn-e-Arabi in his book titled as "Mkkiyah Conquests" and in the story concerning the guest whose religion is not the same as the host's (Ibrahim A's) religion has condemned the act of using any way and method that is based on determination, force or bribery, and concludes that in such cases it is not appropriate to act strictly and severely with the guest and consider him as a foreigner and enemy, rather it is better to adopt the tolerance method as an effective and more serious and deeper way in this regard. Therefore, dealing with trainees in a peaceful manner is considered as one of the main methods of religious education in spiritual approach. The issue of tolerance and not being strict is also in close relationship with pluralistic approach in the context of religion. The result of this pluralistic thought is nothing but negligence and tolerance against the followers of other religion [6]. In relation to the acceptance of religious pluralism, Showan, a contemporary mystical scholar, concludes that from the mystical perspective, each one of the religions, despite their apparent differences and even contradictions in their apparent religious laws, are considered as different 
ways to the same destination. Otherwise, God had closed the salvation ways for the vast majority of people in the past, present and future. According to Quran, a pious, is a virtuous person who has the ability to self-assessment, selfstability, self-monitoring and self-control - the ability which is called virtue. Good behavior and relationship with others is one of the other important characteristics of faithful people that is also emphasized even in relation to nonMuslims and other religions and therefore, the holy prophet (peace be upon him) has been advised in Quran (,Sura Nahl, verse: 125 ) that "Call them to the path of your Lord with wisdom and words of good advice; and reason with them in the best way possible. Your Lord surely knows who strays from His path, and He knows those who are guided the right way". Other features and characteristics have also been mentioned in Quran and other religious contexts such as Nahj-al-Balaghah and narratives for believers. And in the present discussion there is no opportunity to bring them up. We can briefly say that religion-oriented people should enjoy features and attributes such as awareness, insight, attitude, practical commitment, faith, power of virtue and self-control, ability to self-assessment as well as evaluation of others, open mindedness and ability to establish appropriate and logical interactions with others [11]. In this part of the paper we are to deal with different types of religious education models.

\section{General or public religious education}

General religious education means the part of religious teachings that constitute its central core and in fact its conscience. This part includes monotheism, monotheistic characteristics, fixed and universal value-related and ethical teachings that in fact have been based on the unity and the attributes of God and due to comply with its certainty and stability they themselves are also eternal and universal. According to the interpretation of the Quran in some sense, Islam also refers to this section: "Neither was Abraham a Jew nor a Christian, but upright and obedient, and not an idolater" (Sura Al-e-Emran, verse: 67).As a result some part of religious education can be of general or universal because discourse and agreement on it is possible and essentially one of the supreme goals of religious education is also to train this inner part or in another sense "the brain of religion" [3]. Considering this section also leads to maintain and continue the existence of religion and causes increase in its effective role in the field of human life.

\section{Special religious education}

This part of religious education belongs to the area of pluralism and relativism, because here there are tremendous and considerable differences among different religions - differences that cannot be identified and understood, rather their identification is possible through acquisition such as traditional and rational sciences that like experimental sciences that have been dominated by relativism and pluralism and for this very reason cannot be considered as criteria for collective discourse and agreement discourse and they of course cannot be considered as criteria; of course, relativism and plurality governing this part of religious education and teachings don't mean that they are to be ignored and rejected as the pluralism and relativism governing the experimental sciences haven't reduced their importance and value rather they have changed the position of these sciences in human life. Similarly, in the single unit this part of religious education will continue its own living but with a different position compared to our period and previous models. The beautiful example for this position changing is changing the role and position of the part and the sun in solar system according to the Ptolemaic and Copernicus astronomy. Similarly, in the above model of religious education for the unique world mystic part and specific part of religions apply to the sun and planets, respectively. Indeed, the real position of these two parts in the present educational systems is vague and confused so that boundary between them is quite unclear and therefore, the task of religious education is to establish the exact boundary for these parts and to make the educators familiar with the role and position of each one of them (the same source).

\section{Contemporary challenges in terms of religious education post-modernism}

Pluralism is one of the primary principles and elements of post-modernism school. This school disagrees with any centralism, totalitarianism, and belief in authority and denies considering a central reality as important in the life and agrees with pluralism. Since post-modernism denies any generality, post-narrations and on the whole any fixed reality, is not in a good relationship with religion as a back view of the reality because religions in general are seeking an absolute truth. This is why, general atmosphere prevailing the postmodernist education,

Is like the one governing the secularism modernism. The only difference between the two approaches is related to the way they deal with religion. As modernism considers religion as a part of cultural heritage against the science and rationality, consequently, it is to remove it. However, post-modernism accepts and shows the religion as some part of past heritage that one may pay attention to it to some extent and even make use of it as an equipment. On the other 
hand, according to the basic premise of postmodernism on pluralism and respect other cultures, possibility about discussing the religion is provided. In principle like their origins (modernism), post-modernists are to realize a unique world but a world free of problems and crises of modernity and for this reason, in terms of ontology and epistemology encounter the world and people living in the world in a more flexible manner. As a result, their dominant approach is pluralistic and relativistic approach. This pluralistic has in turn added extra maneuverability to the post modernists because theoretically, through this approach gathering different peoples, nations, cultures and sub-cultures under the unique universal umbrella is provided better and more comfortable. Moreover, pluralism creates a situation in which paying attention to religion and religious education is recognized in a formal manner. Hence, it seems that collection between post-modernist religion-orientation and pluralism is provided because religion is not considered superstition either, rather it has its own position and value as a part of human being's cultural heritage, a position which isn't not only lower than science and technology, but sometimes is considered equivalent with it. On the other hand, in globalization process, realization of possibility of pluralism requires democracy and toleration or tolerance and negligence to be considered the most important value and also the top target.

Today's civilization has reduced the world to a small village. Today's civilization has made the man's life longer and has changed the individual into an independent existence. However, despite these achievements, it has deprived the human being for whom perhaps have been all of these tasks. Such contradictions have caused some scholars in the area of education such as Bleak (quoted by Barrent) to come to the conclusion that post modernism hasn't been able to offer a new attitude in the area of education that can practically be substitute by modern thoughts [6]. As previously mentioned, specific religious education in training which takes place for itself in the realm of pluralism, is an inevitable issue in globalization process that we are willy-nilly located in it and this process according to its main sources (modernism and postmodernism) has brought negative consequences as well as positive ones. Spiritual crisis, identity crisis, social crisis (increased drug and crime types and penal offense), intake stroke, the environmental crisis are some of its negative consequences. Globalization process is faced with different paradoxes. Paradoxes that by resorting to the principles and approaches of the current ruler, that is, modernism and postmodernism, it is not possible to carry them. Modernism is caught in the trap of uncertainty and meta-narrative that ultimately leads him toward monopoly, totalitarianism and a kind of dictatorship. Post modernism has also caught itself in complete relativism and pluralism. Relativism and pluralism that leads the man toward utopia and destroys him (the same source).

In fact, education not only is responsible for familiarizing the students with different cultures including new and old, modern and primitive ones, but also is responsible for clarification of effectiveness of each one of them in its social and historical context because according to post modernism, man becomes significant in his social-cultural context.

\section{Pluralism}

Pluralism implies the term of "plurality" and "diversity" and its suffix (ISM) suggests the trend and therefore, it is used in different areas including "religion" and "philosophy" and "ethics" and "law" and "politics" and each school offers its own interpretation about it. In terms of the Quran, religion is to believe a series of ideological, practical and valuable doctrines whose origin and source is God [2]. The word "religion" is among the words and concepts that historians and philosophers of religion and theologians have not yet been able to present an inclusive and exclusive definition for them because there are different ideas and thoughts that call themselves religion. Among these ideals there are so evident differences that share and unity of religions, i.e. the belief in God has itself become the factor of multiplicity and them. In expressing the origin of pluralism it can be said that this issue has been discussed in eastern scientific communities. Damascene Youhanna has also been the inventive of this issue and even has written a treatise about it [5]. In his paper, Ekhvan-al-Safa, has brough up the religious issue of plurality and he says: know that there is the right in any religion, and the right is talked by any language and appearance of pseudo is permissible and possible for any human being. Some people also consider Ibn-e-Arabi among the proponents of legitimacy of all religions. Pluralism, as one of the attractive and noisy theories in the field of studies about religions and philosophy of religion insists on this principle that religious differences should be accepted like cultural differences and differences present among the religions like cultural or racial differences enjoy secondary importance in relation to the common nature of human beings. Holy Quran in many verses has emphasized on the principle of equality of human rights and rejecting any racial, ethnic and linguistic and ... discrimination, and this is the important basis for tolerance. In resurrection, Almighty God will act according to the tolerance and negligence principle with HIS creatures and the majority of people will come to meet heavenly blessings; traditional and intellectual evidence also emphasize on this issue, and Islamic philosophers such as Avicenna and Sadr-al-Motaalehin and some of martyr Motahhari's contemporaries have emphasized this issue (the same resource). 


\subsection{Pluralism and its relationship with Islamic religious education}

In this part of the present research, we will deal with relativity between pluralism and religious education.Pluralism can be studied from two respects: 1. Epistemological pluralism 2. Category related pluralism which is related to the real life. Epistemological pluralism in turn, implies the knowledge. This kind of pluralism primarily refers to the plurality of sources of knowledge and the second concept considers it as relativity of understanding about human being's knowledge. In both sense, the result is accessing the knowledge, interpretations and perceptions; in both cases, that is, plurality of cognition resources and / or relativity of human being's knowledge you may accept a single truth as default. However, if we consider the lack of truth, the result will be nothing but absolute relativity and full validity of pluralism. So with this default (lack of a single truth), surely there will not be possibility of dialogue between pluralism and religion and consequently, religious education including Islamic one. In the latter case, the default placement of the single truth, one can imagine the single truth as two kinds. The first, in a simple form and the second, in a complex form with different layers. Now, if the truth is raised in a simple form, willy-nilly, pluralism also lacks validity and loses its relevance. Because, in this case there is only one correct cognition and perception and other cognitions and perceptions will be considered false and wrong. Conversely, if the truth be thought of as consisting of a layer, the inferred results can be one of the following forms:

\subsubsection{Some comments and impressions, are totally wrong}

It is quite reasonable to say that in relation to the false cases of theorems compared with their true cases, conclusion will be easier and more convenient. Therefore, acceptation of the single truth in a complex and layer form will make the ground ready for denying some of the perceptions and interpretations.

\subsubsection{Imagining that some interpretations and perceptions are completely true}

It should be noted that approval of a preposition is more difficult that its denial. In other words, even if it is determined that a proposition is false, we simply cannot conclude that it is necessarily true. However, in an Aristotelian "zero and one logic" not being false is meant being true. But if we study these prepositions in fuzzy logic system, the judgment will face difficulties. Thus a preposition can be "not false" but we cannot easily comment about its accuracy. On the other hand, because of limitations and inadequacies of human knowledge, it is not possible to make an opinion on accuracy of a preposition in an easy and reliable manner.

\subsubsection{Imagining that some interpretations and perceptions show some part of the reality}

This result is very conservative. In other words, it is neither absolutely false nor absolutely true, rather we reach to a judgment that can bring us closer to the reality and also clear to us some layers of the complex and compound reality, as well as make us free from the trap of absolute relativity in addition to absolute negation. As a result, it is possible to create the possibility of dialogue and reconciliation among the pluralism and religion and religious education.

\subsubsection{Of course we should come to the conclusion about the reality of the religion and its simplicity or its being compound}

It is quite clear that religion cannot be assumed as a single and simple truth. It is true that God is the single and simple truth. However, religion is not equivalent with God; it is a compound reality with both divine and spiritual aspect and earthly and material aspect because one side of it is related to the man and his life in the body of substance and material on the ground. In this regard Nasr says: each particular religion is both absolute religion and a religion. Absolute religion because it has in itself absolute truth and means for its achievement; particular religion because it is proportional to the psychological and mental needs of a specific human being group for whom it has been prescribed and its audience is religion and it emphasizes a certain aspect of the reality [9]. Each religion has its own form. If we simulate different religions to different geometrical forms such as hexagonal, square, etc. - like the supreme of all religions - where different laws are its different manifestations, is similar to a circle which is the most complete shape and other geometrical shapes are shown in it.

Moreover, even the Lord, despite being single and simple, appears in different forms. Thus, according to Mulla Sadra's interpretation we are faced with multiplicity in unity and unity in multiplicity. Then, in the field of religion and consequently religious education the default is a complex reality and a more meaningful layer.

Showan (1997) also states: what determines difference between various forms of the truth, is difference present in man's capabilities. The perfect men who have emerged during thousands of years among their own people more or less have had characteristics of their own race and therefore existence of different and novel acceptors required different radiations of a single reality. The point that should be cleared here is: Although real-Religious pluralism is acceptable and following the outstanding figures and teachers, believers of a special religion deny other religions, religion doesn't mean the acceptance of any claim that has religious form [5]. It is important to note that reality is single and according to Showan's words it is placed "beyond the forms" and in fact it cannot be defined. In this case the view of believers in religion for neorealist perspectives can be closer views. Thoughts that believe in outside reality and truth - not in its 
simple and classic form - like building a puzzle, recognize the pieces step by step and place them in their own places. Of course the wrongness of some attempts is completely evident. Thus, the best result to be achieved is that any interpretation and perception may be false or in some extent true. However, in order to get to the truth we cannot deem the perception as sufficient rather for the purpose of better cognition the wider and deeper path is still open. In this way some kind of cognitive pluralism is approved because various sources of knowledge is available and also the human knowledge is relative. Now one should think about the fact that in education process with validity for being accepted by pluralism, any attempt can be regarded a step on the path to truth. In addition to the above discussion that theoretically deals with this issue, as it was previously mentioned pluralism can be studied in terms of human life, that is, its practical aspect. In order to study the reality of human life we can look up the life history of human beings. For example if we study the history of Muslims, we will clearly find out that occurrence of different intellectual interpretations had been appeared from the very beginning of Islam; Movements such as Mu'tazilah school, Ash'ari, various philosophical school (taking their differences and diversities into account), traditional schools (fiqh and hadith), Sufism and mystic [1].Yet it may be argued that we cannot easily and simply reject all of these attempts that have occurred within the framework of Islamic teachings and based on the Quran and for instance from among these attempts choose one and only one specific approach as the reality. It is clear that for the purpose of such a choice we need powerful and strong reasons, and also defined indexes; while determination of indicators and provision of reasons, in turn refer to these schools and natures. In other word, logically we will be caught in "vicious circle". So, at least all of these schools and movements can be considered as attempts to achieve the complex and layered reality that somehow have been able to show at least part of the reality and of course not all of it. This means that some of these efforts have also been wrong. As a result, history and real life scene of people are also proofs for validity of cognitive pluralism. Of course, as it was discussed previously, within the framework of religious ideology, pluralism is as an attempt that step by step takes us toward some parts of the reality.

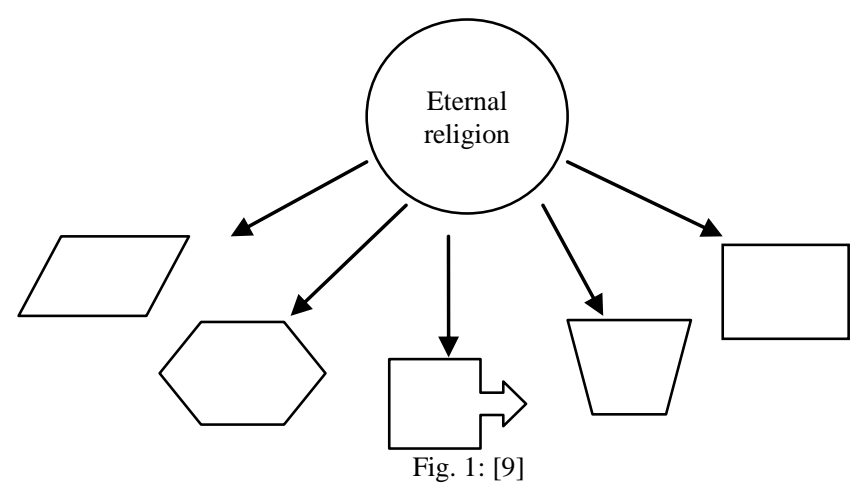

\section{Summarizing and conclusion}

On the whole, arguments made in this regard made it clear that due to giving validity to epistemological pluralism, any attempt can be considered as a step toward achieving the truth and for this reason it is considered valid yet not a representative of undisputable truth. On the other hand, due to giving validity to historical pluralism, it can be concluded that: this course, that is, occurrence of different interpretations and intellectual approaches and cognitive movements should be continued. In terms of knowledge, diversity and plurality of different opinions and ideas can be considered helpful in order for achieving and step by step approaching to the reality and being evolved in this course. Training in the age of knowledge and developments should be an outcome of some kind of mutual understanding of the world. People should gain deep and internal awareness concerning their foundations and cultural roots and also they should learn to respect other cultures and religions. Furthermore, real education is not a dogmatic education; rather it should open the way for explaining and adopting the issues in logical and rational manners. As a result, this kind of attitude has been created due to some kind of tolerance and interaction based on the criteria of reason and logic and if true and right speeches are offered by other people, they will logically be dealt with. So it is suggested that in line with this research relationship of religious education with other educational components such as such as critical thinking and its relationship with the subject to be studied and discussed. Also, the administrators and curriculum planners and education experts in educational and training programs should redefine the methods and components of academic curriculum based on such ideas and subjects. 


\subsection{Consequences of this approach to Islamic education are as follows:}

1) Providing more fertile ground for theorizing in the field of Islamic education.

2) Considering the freedom in Islamic education as authentic and as a branch of knowledge in order to generate theories and approaches.

3) Providing the possibility for understanding different intellectual approaches and movements in Islamic religious education for trainees.

4) Addressing the concept of religious education as an effort and an epistemological process.

5) Removing monophonic mood of religious education and mood of single readout.

Education in the era of galactic explosion of information and increasing coexistence, intentionally or unintentionally should prepare the trainee for interaction, Selection, acceptance or rational rejection because full acceptance or full rejection of the issues is neither rational nor appropriate and nor possible. For this reason normative components of knowledge, reasoning, interaction and tolerance are among the characteristics of leading Religious Education in the contemporary era. At the current circumstances religious education cannot be successful relying exclusively on safetyoriented approach based on monopoly of privacy or restrictive approach because cognitive and cultural place and time barriers, and previous structures cannot either have a decisive role on religious education process. Thus, religious education based on pluralism approach can be effective in training the people, who can lead their spiritual and human lives due to freedom and awareness and constructive interaction with the worldwide.

\section{References}

[1] Saeed, Ismaeel Ali, et.al. Schools and educational trends in Islamic civilization. Translated by Behrooz Rafiee. Tehran. SAMT. (2001).

[2] Richards. Galin.Towards the theology observer of all religions. Translated by Reza Gandomi. Nasrabadi and Ahmadreza Meftah. Tehran. Center for religious research and studies. (2001).

[3] Shamshir, Baabak "Roots of contemporary global challenges and crises, and the role of mystical religion in their reduction". Paper presented at the Conference on Interfaith Dialogue. (2003).

[4] Shamshiri, Babak "Globalization and religious education from modernism point of view, Post modernism and Islamic mysticism". The 8th conference of Iranian Curriculum Studies Association, Abadan (2008).

[5] Kadivar, Mohsen and Karami, Taiebeh. "Relationship of plurality of human beings with the number of religions and idea of transcendent unity of religions" Scientific-research quarterly of religious thought - University of Shiraz, No. 12. Pp123-134(2004).

[6] Shamshiri Baabak "Education from the view point of love and mysticism".Tehran. Tahoori. (2006).

[7] Arsaan, Keelaani, Maajed "Training opinions course in Islamic civilization". Translated by Behrooz Rafeiee, Qom, Institute of university domain. . (2008).

[8] Marzooghi. Rahmatollah "Fundamentals of principles and new developments in contemporary education". Takht-e-Jamshid publication. University of Shiraz. 1st edition. (2012).

[9] Nasr, Seyyed Hossin ,. Ideals and realities of Islam ,Londom : George Allen \& Unwin LTD. ( 1971 )

[10] Schuon, Frithj of Gnosis - Divine Wisdom, London: john Murrag (1950).

[11] Schuon, Frithj of, (. Light on the Ancient worlds, L. Northbourne (tran.), U. S. A: World wisdom Books 1984. 